\title{
A mHealth-based Nursing Model for the Health Outcomes of the Discharged Patients with Nasopharyngeal Carcinoma: a Pilot RCT
}

\author{
Tingting Liao \\ First Affiliated Hospital of GuangXi Medical University \\ Liyan Qiu \\ First Affiliated Hospital of GuangXi Medical University \\ Jingwen Zhu \\ First Affiliated Hospital of GuangXi Medical University \\ Jiayan Li \\ First Affiliated Hospital of GuangXi Medical University \\ Yanxin Zhang \\ First Affiliated Hospital of GuangXi Medical University \\ Li Yang ( $\sim 2452688696 @ q q . c o m$ ) \\ First Affiliated Hospital of GuangXi Medical University
}

\section{Research Article}

Keywords: mHealth, nasopharyngeal carcinoma, nursing model, health outcomes

Posted Date: October 8th, 2021

DOI: https://doi.org/10.21203/rs.3.rs-825047/v1

License: (c) (1) This work is licensed under a Creative Commons Attribution 4.0 International License. Read Full License 


\section{Abstract}

Background: Nasopharyngeal carcinoma (NPC) is the most prevalent cancer in China, accounting for an incidence rate of $12.5 / 37$ in Guangxi, which is the highest in the world. Although chemoradiotherapy offers more effective cancer treatment, it also causes a variety of acute and chronic side effects, seriously affecting the quality of life. NPC has evolved into a chronic disease with most patients opting for home-based rehabilitation. Therefore, efforts on improving the home-based extended care services to improve the quality of life of patients are booming. The Chinese government encourages the use of internet technology for expanding the prospect of nursing.

Methods: An experimental design was applied for this study. The study enrolled 116 discharged patients who were re-examined in the Radiotherapy Department of the First Affiliated Hospital of Guangxi Medical University from November 2019 to February 2020. The patients were divided into a test and a control group ( $\mathrm{n}=58$ cases in each group) using the IBM SPSS STATISTICS 20.0 random number generation method. The control group was subjected to routine discharge guidance and follow-up, while the experimental group was implemented with a mobile health (mHealth)-based continuous nursing intervention model. The scores of the side effects, cancer fatigue, and quality of life were compared between the two groups of patients for 3,6 , and 12 months, respectively after discharge from the hospital.

Results: This study included a total of 114 patients, and there was no significant difference in the baseline data between the two groups. After 6 and 12 months of intervention, the severity of radiation toxicity and side effects, scores of cancer-related fatigue, and quality of life (symptom field) of the patients in the interventional group were significantly lowered statistically compared to those in the control group.

Conclusion: This study is based on the mHealth continuous nursing intervention model, which can better guide discharged patients to master the correct rehabilitation nursing methods, and reduce the side effects of radiotherapy and cancer fatigue.

Trial registration: This study was retrospectively registered as a randomized controlled trial in the Chinese Clinical Trial Center. Registration Date: January 12 , 2021, Registration Number: ChiCTR2100042027.

\section{Introduction}

Nasopharyngeal carcinoma (NPC) is a head and neck malignant tumor originating from the nasopharyngeal epithelial cells (Chang \& Adami, 2006), It has a high incidence in Guangxi of China, the annual crude incidence being 30-80/ 100,000 (Strazzulla, Barreca, Giancotti, Pisani, \& Torti, 2015; Tang et al., 2016). Radiotherapy combined with chemotherapy is so far, the best treatment for NPC owing to characteristics like NPC cell differentiation and high sensitivity to radiation. The present 5-year overall survival rate in an NPC patient with such combinatorial treatment exceeds $80 \%$ (Jemal et al., 2011). However, chemoradiotherapy not only resists the tumor cells but also inevitably damages the normal tissues in the vicinity of the radiation field area, resulting in acute and chronic radiation injury symptoms such as the oropharyngeal acute mucosal injury, dry mouth, taste change, difficulty in opening the mouth and swallowing (Xiao et al., 2013; Yi \& Qiang, 2017). These long-term toxicities and side effects syndrome tend to exist for a long time in the patients during the home rehabilitation period even after the treatment is terminated. It is during this post-treatment period that the body's symptoms group and the negative emotions cooperate and reinforce each other, aggravating the burden of cancer on the patients (Gift, Stommel, Jablonski, \& Given, 2003). In addition, the nonstandard follow-up management, as well as the lack of access to health knowledge, seriously jeopardize the quality of life(QOL) of the NPC patients outside the hospital. Therefore, there is an urgent need for systematic and effective continuous nursing services to improve the correctness of the health behavior as well as meet the needs of personalized care (Chow, Wong, Chan, Chung, \& Lee, 2010; Shi et al., 2015). Therefore, the NPC patients not only need to prolong their survival time but also medical staff to provide long-term, professional and timely continuing nursing services to improve their QOL.

Continuous care is considered one of the essential elements of high-quality health services (Min, Guohong, \& Yang, 2015). It refers to the systematic, continuous, coordinated, and professional health care behavior that is conducive to the home-based rehabilitation of the patients in the unusual medical service institutions or the same medical service institutions under different conditions (King, Jones, Mccarthy, Rogers, \& Nazareth, 2009). China has established a continuous nursing mode, making initial progress in the field of chronic diseases based on the lessons drawn from the overseas extended service modes and combining them with the characteristics of the domestic medical resource system. For example, the $4 \mathrm{C}$ extension service mode and effect evaluation scheme has been constructed in Hong Kong and Taiwan (Shu-Hua, Ji-Jun, \& Jian-Hua, 2007; WANG Shao-ling, 2009). In mainland China, continuous nursing services are widely executed through telephonic calls, (Jianbo \& Haiying, 2009), QQ, WeChat (Lijun, Shuang, \& Hui, 2018), mobile health app (GUO Ming juan, 2017), and other media. These discussion platforms provide practical and theoretical bases for continuing nursing in the future, and also expose the deficiencies of the current extended nursing service teams and intervention programs in China, like: (1) The diversified and single forms of continuous nursing exist side by side, while each form of continuous nursing is fraught with limitations (Qiao-Qin, Li, Shu-Xiao, Nursing, \& University, 2013); (2) The implementation plan and operation process of continuous care in the hospital has no relevant theoretical guidance and standard, or unified evaluation system (Shi-Ying, Shu-Hua, Yi-Gang, \& Jin-Hua, 2009); (3) Presently, the hospital discharge follow-up and community-based primary health care services constitute the common modes of implementing continuous care in China (Qiao-Qin et al., 2013), However, about 93.75\% of the patients wish to receive extended care services and on-site services after discharge, and about $90 \%$ of expect the hospital to undertake this work (Hui et al., 2015). However, the continuous care link in hospitals is relatively weak, and the contradictions between the supply and demand of the extended nursing services is very prominent due to limitations such as uneven distribution of medical resources and insufficient development of communities. Therefore, this study mainly focused on optimizing the therapeutic resources to help hospitals in providing the patients with high -quality, effective, convenient, and rapid continuation of nursing services for ameliorating the current situation of unbalanced development of medical resources.

The robust development of the mobile Internet has solved the issue of hospital -based continuous care (Ying, 2017). The 43rd report of the China Internet Network Information Center (CNNIC) in 2018, as of December 2018 stated that the network penetration rate reached 59.6\%, and the proportion of using mobile phones to connect to the Internet was as high as $98.6 \%$, maintaining a benign growth trend. The WeChat public platform is present, the most widely used 
internet platform. It is extensively used for the hospital health knowledge release, online appointments, disease intervention, and other fields and can realize the comprehensive interaction of text, pictures, and sounds (Feng et al., 2017; Gao, Zhou, Liu, Wang, \& Bowers, 2017). The 2016-2020 China nursing development planning document also encourages the use of mobile network technology for improving the level of hospital informatization, extending nursing services to the communities and families, and providing one-stop flexible extension services for the discharged patients to meet their health needs (China, 2017). The research has shown that the efficient and convenient use of the internet, the follow-up management system can overcome limitations of time and space in traditionally implementing continuous nursing, accelerating the dissemination of health knowledge, improving the enthusiasm of the individual behavior and user experience, and thus, enable the patients to achieve a higher quality and effective management (Luo Huiyu, 2017).

Therefore, our team has used the internet technology to build a mHealth platform for the NPC patients relying on the WeChat public platform to provide them with good familial extended care. The aim involved exploring the impact of the mobile health care model on the health outcomes of the discharged NPC patients in terms of radiotherapy, fatigue, and quality of life.

\section{Methods}

\subsection{Study design}

This study is an exploratory pilot study based on a randomized controlled trial lasting from November 2019 to December 2020.

\subsection{Patients}

The study involved NPC patients who were recruited after reviewing in the Radiotherapy Department of the First Affiliated Hospital of Guangxi Medical University from November 2019 to February 2020.

\section{Inclusion criteria}

(1) The patients diagnosed by pathology and who have completed chemoradiotherapy; (2) Those aged 18-65 years; (3) With no previous history of mental illness and serious disturbance of consciousness; (4) With an educational level of primary school or above; (5) Having the ability and condition of using the Internet; (6) Were informed and voluntary participants.

\section{Exclusion criteria}

(1) The patients with distant metastasis or recurrence; (2) Those with language communication and hearing impairment; (3) Combined with other serious diseases or organic malignant tumor.

\section{Dropout criteria}

(1) Included the dropout and non-compliance; (2) Recurrence, metastasis, or death.

\subsubsection{Sample size calculation}

According to the sample size calculation formula involving the comparison of the two sets of means, the sample size was calculated after consulting the literature, such that the two-sided $a=0.05, \beta=0.10$, and the proportion of the two groups of samples is the same, that is, $r=1$. After preliminary experiments, the $\sigma=4.98, n_{c}=50$ cases were calculated taking into account the $10-15 \%$ loss to follow-up rate, with $n_{c}=58$ cases, according to the average and standard deviation of the total score of cancer fatigue after 3 months of intervention for the two groups of patients. There were 58 cases in the control group. Therefore, a total of 116 cases were required.

The formula used is as follows:

$$
n_{c}=\frac{(r+1)}{r} \frac{\sigma^{2}\left(Z_{1-\alpha / 2}+Z_{1-\beta}\right)^{2}}{\left(u_{t}-u_{c}\right)^{2}}
$$

where $r$ is the sample ratio of the two groups, $u_{t}$ and $u_{c}$ are the mean values of the two groups, $\sigma 2$ is the combined variance, and $n_{c}$ is the sample size of the control group.

\subsubsection{Randomization, assignment, and hiding}

In this study, the IBM SPSS STATISTICS 20.0 random number generation method divided the patients into the experimental group and the control group with 58 cases each. (the IBM SPSS STATISTICS 20.0 software is a professional data statistical analysis software developed and continuously updated and improved by Norman H. Nie, C. Hadlai (Tex) Hull and Dale H. Bent, three graduate students from Stanford University in the United States.). After the participants expressed their interest in the research, the research recruiters used the IBM SPSS STATISTICS 20.0 software for randomized allocation. The researchers could not be blinded due to the inconsistent intervention tools between the two groups of patients. The allocation ratio of the intervention to control was 1:1.

\subsection{The clinical teams}


(1) Composition of the nursing team: The chief leader was the director of the radiotherapy department and the director of the nursing department, who was responsible for the operation of the whole team; the deputy leader was the head nurse, who assisted the whole team to carry out nursing. The members included 5 nursing staff of the radiotherapy department, 2 attending physicians, 1 graduate student, 1 dietitian, and 1 network engineer, with clear responsibilities assigned. (2) The team training: the training content involved the system platform and operation platform, the use and maintenance, data collection and input, the continuation of the nursing intervention methods, specialized nursing knowledge and techniques of the centralized and unified training, to ensure that the research and control the consistency of the implementation of prejudice, ensuring that every member is the master for platform operation, problem handling, and answering questions in the process of diagnosis and prognosis. (3) The responsibility and role allocation: the nursing members were responsible for the establishment of the patients' health records, formulation of the discharge plan, knowledge push, answer questions. The doctors participated in the formulation of follow-up plans for patients discharged from the hospital and answered questions online.

\subsection{Intervention measures}

Control group: There was routine discharge guidance and follow-up by the department follow-up staff every 3 months through telephone follow-up and outpatient follow-up guidance for understanding the side effects of the radiotherapy in the patients after discharge, and providing diet, oral care, functional exercise, follow-up, and other instructions. Experimental group: Based on the mobile health care model. detailed as follows:

\subsubsection{Construction of the mobile health (mHealth)-platform}

Mobile health (mHealth) was developed by a unified team of experts comprising those from the Radiation Oncology Department of the First Affiliated Hospital of Guangxi Medical University and an information technology company. According to the needs of the patients after discharge from the hospital, the characteristics of recovery, and the use of "Internet +" media technology, the research, and development was simple, and fully functional mobile health (mHealth) platform without installation. The platform architecture involved a system management platform and an operating platform. The system management platform had functions such as information management, data management, and platform maintenance. The operating platform: ran in the form of "WeChat Mini Program." $\otimes$ Patient end: with functions of health knowledge base, online consultation, data upload, personalized management, and health file; $₫$ Medical end: high-quality nursing resource sharing module; खPatient library; खOnline clinic; $₫$ Doctor information.

The details are as follows:

\section{(1) Service platform:}

A patient side: 1) Common interface: $₫$ Knowledge database: it includes 5 types of knowledge for the patients to read and browse; $邓 0$ line consultation module: the patients can interact with the medical staff online to consult the basic knowledge of the disease, personalized dietary guidance, symptom management, emotional management, medication guidance, and other issues; $\square$ Data upload module: used for collecting the patient's weight, blood routine, and other relevant health data, to facilitate the medical staff to timely grasp the patient's recovery. 2) Personal interface: My health files module: includes the basic information of the patients. Personalized demand knowledge module: the nursing team customized the personalized discharge plans and health education plans for the patients according to their nursing problems, complications assessment, and needs, and regularly sending them to the patients for 2 weeks (Figure 1).

B Medical care side: The members of the continuous care team carried out the continuous care services through the functional modules customized at the medical care side. The medical side includes $\otimes$ My patient database managed the patients who entered the home care platform, the patient's name, height, contact information, personal contact information, whether allergic drugs, and other information could be checked. $₫$ Online q\&A carried out the basic continuous care services, such as online $q \& A$, providing the personalized guidance and health-related knowledge, operation guidance, reminder reading, and other follow-up content. $\nabla$ The high-quality nursing resource sharing module: available on the public interface, the activities that could be browsed, technology development, and high-quality clinical nursing resources of our hospital, enriched the professional technical knowledge and improved the professional level (Figure 2).

(2) System management platform: It has five management modules: community management (the discharged patients in different regions), user management (medical care management and patient management), article and video, questionnaire, and statistical data management. The platform maintenance, and management, editing, updating, and pushing of health knowledge, questionnaire pushing, data statistical analysis, and other functions can be carried out according to the five management modules (Figure 3).

\subsubsection{System security policy}

The security of the platform: (1) Signing the confidentiality contracts with the technology developing companies to avoid breach of the patient privacy; (2) The use of cloud computing server, virtual firewall, role permission control, and other security operations. In addition, the managers should sign the relevant confidentiality agreements for software development, data transmission, and patient management for protecting patient privacy.

\subsubsection{Application Security}

The platform has both the function of authority and security management: hence, two levels of permissions are set in the medical terminal. The first level of authority is the super administrator responsible for managing the account and password of the team members, the setting of patients' admission, as well as the operation and maintenance of the platform. The team members can join the medical terminal only after the super administrator grants the invitation code, and it is involved in the micro signal. To ensure security, others are barred from logging in to the medical terminal using their account. The second level of authority is involved those of the nursing team members responsible for regularly releasing video and audio health education materials, questionnaires, 
answering the questions of the patients. The patients and the families are only limited to use their rights. With the help of the security function of the WeChat software account management, information security was ensured since other accounts can't be logged in without the authorized permission.

\subsubsection{Data access security}

The platform was bound to a WeChat account and needed registration so that other accounts were barred from logging in ensuring the confidentiality of patient information; patients and families were only limited to use the rights and could only access the functions and contents that should be seen within their authority.

\subsubsection{The intervention group}

Before discharge: The patients in the intervention group were registered by scanning the QR code of the "mini-program" or following the "family continuation care" mini-program, and the electronic health records of the patients were established for improving the patient's health information: name, home address, mobile phone number, disease diagnosis, discharge time, current weight, etc. The operation of the platform being simple and easy to understand, ensured that patients would be proficient in using all the functions (Figure 4).

\section{After discharge}

The intervention group implemented the nursing intervention based on the "Internet +" continuous nursing platform, based on the conventional nursing method of the control group, as follows

\section{(1) Individualized assessment of the health problems of the patients}

It included nutrition, sleep, exercise, psychology, etc. The specialist assessment included nasal congestion, hearing loss, dry mouth, difficulty in opening mouth, radioactive decay, and other toxic side effects. It provided the basis for compiling the mobile education knowledge base and personalized push in the later period.

(2) Establishment of the mobile health education knowledge base: A combination of the literature knowledge and existing problems and needs of patients to develop a knowledge base. The content of the knowledge base was edited by the continuing care team, using pictures and videos to ensure the ease of understanding, in a readable and professional manner. It included horizontal classification and personalized vertical knowledge classification. The horizontal classification comprises four health information modules: "life care", "symptom management", "emotional management" and "basic knowledge of disease". The vertical classification is based on the horizontal classification according to the number of questions raised by the patients, the changing trend of radiation toxicity, negative emotions, nursing needs, and other factors. Both the horizontal and vertical classifications are scientific, easy to read and meet the needs of the patients at all levels after discharge.

\section{(3) Health information push}

Based on the common problems and needs of the patients, health information was updated regularly by the nursing team in the form of videos or pictures on the public interface of family extended nursing once every 2 weeks, and reminded the readers of the contents of the basic knowledge of the disease emotion management, life care, and symptom management.

\section{(4) Personalized care:}

1) According to the results of the individualized assessment, the symptoms, psychology, nutrition, and sleep problems of the patients were analyzed, The initiative to answer and guide online with words, pictures, and voice were taken, and the corresponding knowledge from the health education knowledge base were selected and the personalized knowledge module of patients were pushed timely, facilitating the patients to view, improve their knowledge reserve, meet their personalized nursing needs, and promote the patients to take effective health care behaviors.

2) Online interaction: the patients could browse the rehabilitation knowledge of "life care, disease knowledge, emotion management, symptom management" in the "health information module" of the "patient side"; if in doubt, they can consult with medical staff about the nursing knowledge through the "online consultation" module. The team members could click to view according to the message to answer and guide the patients' questions.

3) The continuous nursing team in the "My patient database" urged and instructed the patients to clock in and upload the exercise videos for functional exercises in cases where were mouth opening difficulty and neck fibrosis every week to ensure the correctness of the nursing behaviors.

4) The patients were reminded to browse the latest published knowledge, monitor the reading volume of the patients in the background, and encourage and urge patients to actively and timely browse and self-learn.

5) Data upload: This reminded the patients to upload the weight, blood index, and examination reports, which were convenient for the medical staff for consultation and guidance.

(5) Phased evaluation: The toxicity and side effects questionnaire, quality of life scale, and cancer fatigue scale were used to collect and evaluate the patients at 3, 6, and 12 months after the intervention, and the intervention scheme was continuously and dynamically optimized.

\subsection{Instruments}

2.5.1 General situation questionnaire It included the general baseline data (gender, age, occupation, education level, etc.) and disease data. 
2.5.2 Toxic side effects of radiotherapy It was evaluated by the oncology Radiotherapy and RTOG Acute Radiation Injury Classification Standard. (Cox J D, 1995). The specific rating criteria are as follows:

(1) Dry mouth: grade 5, Grade 0: no change; Grade 1: slight, slightly dry mouth during night sleep; Grade 2: mild, less saliva, does not affect eating and speaking; Grade 3: Frequent dry mouth, little and sticky saliva, plenty of water for eating or speaking; Grade 4: Dry mouth causes a burning sensation in the mouth, very little saliva, difficult speech, chewing and swallowing.

(2) Nasal congestion: grade 4, grade 0: none; grade 1: occasional nasal obstruction; grade 2: equivalent, nasal obstruction at or above 2 times a day, affecting sleep; grade 3: extremely persistent nasal obstruction, open mouth for breathing.

(3) Tinnitus: grade 4, grade 0: none; Grade 1: Mild tinnitus, which occurs only in a quiet environment and does not affect sleep; Grade 2: Tinnitus is loud, the general environment can be heard, does not affect the rest; Grade 3: Any environment can be heard, affecting sleep work.

(4) Trismus: grade 5, Grade 0: no change; Grade 1: Limited opening, incisor pitch 2.1-3.0cm; Grade 2: Difficulty in eating, incisor distance 1.1-2.0cm; Grade 3: Difficulty in feeding soft food, $0.5-1.0 \mathrm{~cm}$ incisor distance; Grade 4 : Incisor spacing $<0.5 \mathrm{~cm}$, requiring nasal feeding.

(5) Neck fibrosis: Grade 4, grade 0: no change; grade 1: mild, skin elasticity is poor, pigmentation or decline, and activity is fair; grade 2: moderate, skin inelastic, head rotation $<90$ and $>45^{\circ}$ to the left or right; grade 3 : severe, skin plate or/and contracture, head rotation $<45^{\circ}$ to the left or right.

2.5.3 Cancer-related fatigue assessment It was assessed using the Cancer Fatigue Scale (Okuyama et al., 2000). There were 15 items and 3 dimensions: physical fatigue, emotional fatigue, and cognitive fatigue. All items were scored by Likert's 5 -level scoring method ( 1 point = none at all, 2 points = very little, 3 points = a little bit, 4 points = quite a lot, 5 points = very much). The total fatigue score range was 0-60 points, 0 points indicated no fatigue state, the higher the score, the more serious the fatigue symptoms, the better the Chinese version of the scale had good credit The Cronbach's a coefficient of the total scale was 0.88 .

2.5.4 Quality of life assessment The quality of life of NPC patients was assessed using the EORTC QLQ-H\&N35(Chie, Hong, Lai, Ting, \& Hsu, 2003). The scale includes 7 symptom areas and 35 items in total. Likert 4 rating methods are adopted for each item, and the score ranges from "no" to "persistent existence". The original score of each field can be obtained by adding the scores of items included in each field and dividing them by the number of items included. Further, the range method is adopted to carry out a linear transformation, and the original score is converted into a standard score of $0 \sim 100$ points, to make each field comparative. The higher the score or the more problems in the seven symptom areas, the poorer the overall quality of life. The Cronbach's coefficient in all fields of the scale is $\geq 0.70$, with good reliability and validity.

\subsection{Data collection procedure}

The general data, radiation toxicity and side effects, cancer fatigue, and quality of life scores of the patients in both the groups were collected by the members of the continuation nursing team before and after the intervention at 3,6 , and 12 months, respectively. Telephone follow-ups were utilized to collect information from the patients in the control group, and platform questionnaires or telephone follow-ups were used for collecting the patients in the intervention group.

\subsection{Statistical analysis}

The programs Microsoft Excel, and IBM statistics SPSS 20.0 were used for data entry as well as statistical description and analysis, respectively. The difference was statistically significant $(P<0.05)$. The data following the normal distribution were expressed as mean \pm standard deviation, and the counting data was expressed by the number of cases (\%). The independent sample $t$-test and repeated measurement analysis of variance were used for measuring data, the chi -square test for counting data, and the nonparametric test for grade data.

\section{Results}

This study involved a total of 116 patients who were randomly allocated, with 58 patients each in the control and intervention groups (CONSORT Figure 5). During the implementation of the project, there was one dropout in the control group due to the loss of follow-up, and one dropout in the intervention group due to distant metastasis. The total dropout rate was $1.72 \%$. In the end, 57patients in the control and intervention groups completed the trial.

\subsection{General data of the patients}

There was a total of 114 patients comprising 57 in the control group and 57 in the intervention group. A chi-square test or independent -sample $t$-test compared the general data characteristics of the two groups, and the difference was not statistically significant $(P>0.05)$, indicating that the two groups were comparable. (Table 1) 
Table 1

Baseline characteristics $(n=114)$

\begin{tabular}{|c|c|c|c|c|}
\hline \multirow[t]{2}{*}{ General situation } & \multirow{2}{*}{$\begin{array}{l}\text { Control group } \\
\mathbf{n}=\mathbf{5 7}\end{array}$} & \multirow{2}{*}{$\begin{array}{l}\text { Intervention group } \\
\mathbf{n}=\mathbf{5 7}\end{array}$} & \multirow{2}{*}{$t / \chi^{2}$ value } & \multirow[t]{2}{*}{$P$-value } \\
\hline & & & & \\
\hline Age & & & 1.090 & 0.580 \\
\hline 18- & $28(49.1)$ & 25(43.9) & & \\
\hline $45-$ & $28(49.1)$ & $30(52.6)$ & & \\
\hline $60-$ & $1(1.8)$ & $2(3.5)$ & & \\
\hline Sex & & & 2.090 & 0.148 \\
\hline Man & $44(77.2)$ & $37(64.9)$ & & \\
\hline Female & $13(22.8)$ & $20(35.1)$ & & \\
\hline Marital status & & & 0.704 & 0.402 \\
\hline Unmarried & $4(7.0)$ & $2(3.5)$ & & \\
\hline Married & $53(93.0)$ & $55(96.5)$ & & \\
\hline Education level & & & 1.880 & 0.598 \\
\hline Primary school and below & 12(21.1) & $17(29.8)$ & & \\
\hline Junior high school & $28(49.1)$ & $27(47.4)$ & & \\
\hline High school/technical secondary school & $7(12.3)$ & $7(12.3)$ & & \\
\hline College or above & 10(17.5) & $6(10.5)$ & & \\
\hline Monthly household income & & & 0.799 & 0.671 \\
\hline$<3000$ yuan & $37(64.9)$ & $40(70.2)$ & & \\
\hline $3000-5000$ yuan & $16(28.1)$ & 12(21.0) & & \\
\hline$>5000$ yuan & $4(7.0)$ & $5(8.8)$ & & \\
\hline The payment method of medical expenses & & & 1.614 & 0.204 \\
\hline New rural cooperative medical system (NCMS) & $43(75.4)$ & 42(73.7) & & \\
\hline Urban medical insurance (URBMI) & $14(24.6)$ & $15(26.3)$ & 0.046 & 0.830 \\
\hline \multicolumn{5}{|l|}{ Family history } \\
\hline No & $8(14.0)$ & $6(10.5)$ & 0.326 & 0.568 \\
\hline Yes & $49(86.0)$ & $51(89.5)$ & & \\
\hline Disease staging & & & 2.527 & 0.112 \\
\hline Phase II and below & $6(10.5)$ & $6(10.5)$ & & \\
\hline Phase III & $21(36.9)$ & $25(43.9)$ & & \\
\hline Phase IV & $30(52.6)$ & $26(45.6)$ & & \\
\hline $3.58 \pm 0.96$ & $3.28 \pm 0.86$ & $1.744^{1)}$ & 0.084 & \\
\hline Treatment plan & & & 0.049 & 0.862 \\
\hline Induction chemotherapy + concurrent chemoradiotherapy & $14(24.6)$ & $13(22.8)$ & & \\
\hline concurrent chemoradiotherapy & $43(75.4)$ & $44(77.2)$ & & \\
\hline
\end{tabular}

Note[1) as the $t$ value

\subsection{Toxicities and side effects of radiotherapy before and after intervention}

There was no significant difference between the two groups before the intervention $(P>0.05)$ (Table2). After 3 months of intervention, there was no significant difference in the severity of symptoms like dry mouth, nasal congestion, tinnitus, trismus, and neck fibrosis between the intervention and control groups $(P>$ 0.05). After 6 and 12 months of intervention, the severity of the above symptoms like dry mouth, nasal congestion, tinnitus, trismus, and neck fibrosis in the intervention group was lower than those in the control group, and the difference was statistically significant $(P<0.05)$,(Table 3$)$ 
Table 2 Comparison of toxicity and side effects of radiotherapy between the

two groups before intervention $(n=114)$

\begin{tabular}{|c|c|c|c|c|}
\hline \multirow[t]{2}{*}{ General situation } & \multicolumn{2}{|c|}{ Before the intervention } & \multirow[t]{2}{*}{$Z$ value } & \multirow[t]{2}{*}{$P$ value } \\
\hline & $\begin{array}{l}\text { Control group } \\
(n=57)\end{array}$ & Intervention group ( $n=57$ ) & & \\
\hline Nasal congestion & & & -1.382 & 0.167 \\
\hline Grade 0 & $23(40.4)$ & 19(33.3) & & \\
\hline Grade 1 & 18(31.6) & 10(17.5) & & \\
\hline Grade 2 & $6(10.5)$ & 17(29.8) & & \\
\hline Grade 3 & 10(17.5) & 11(19.3) & & \\
\hline Dry mouth & & & -0.137 & 0.891 \\
\hline Grade 0 & $2(3.5)$ & $1(1.8)$ & & \\
\hline Grade 1 & $6(10.5)$ & $4(7.0)$ & & \\
\hline Grade 2 & 18(31.6) & 19(33.3) & & \\
\hline Grade 3 & $26(45.6)$ & $32(56.1)$ & & \\
\hline Grade 4 & $5(8.8)$ & $1(1.8)$ & & \\
\hline Tinnitus & & & -0.804 & 0.421 \\
\hline Grade 0 & $29(50.9)$ & $23(40.3)$ & & \\
\hline Grade 1 & $7(12.3)$ & $9(15.8)$ & & \\
\hline Grade 2 & 11(19.3) & $16(28.1)$ & & \\
\hline Grade 3 & 10(17.5) & $9(15.8)$ & & \\
\hline Trismus & & & -1.531 & 0.126 \\
\hline Grade 0 & $45(79.0)$ & $51(89.4)$ & & \\
\hline Grade 1 & $10(17.5)$ & $5(8.8)$ & & \\
\hline Grade 2 & $2(3.5)$ & $1(1.8)$ & & \\
\hline Neck fibrosis & & & -0.540 & 0.590 \\
\hline Grade 0 & $46(80.7)$ & $48(84.2)$ & & \\
\hline Grade 1 & $6(10.5)$ & $6(10.5)$ & & \\
\hline Grade 2 & $5(8.8)$ & $3(5.3)$ & & \\
\hline
\end{tabular}

\subsection{The cancer-related fatigue score before and after the intervention}

There was no significant difference in the CRF score between the two groups before the intervention $(P>0.05)$. After 6 and 12 months of intervention, the scores of total fatigue, physical fatigue, emotional fatigue, and cognitive fatigue in the two groups were lower than those in the control group, with a statistical significance $(P<0.05)$. The results of the repeated measurement ANOVA with two samples showed that, extending the intervention time significantly lowered cancer in the two groups than that in the control group $(P<0.05)$. After 6 and 12 months of intervention, the score of the cancer fatigue in the intervention group was lowered than that in the control group $(P<0.05)$, (Table 4$)$. 
Table 3 Comparison of toxicity and side effects of radiotherapy between the two groups after intervention $(n=114)$

\begin{tabular}{|c|c|c|c|c|c|c|c|c|c|c|c|c|c|}
\hline \multirow[t]{2}{*}{ Project } & \multirow[t]{2}{*}{ grading } & \multicolumn{2}{|c|}{$\begin{array}{l}\text { Three months after the } \\
\text { intervention }\end{array}$} & \multirow[t]{2}{*}{$\begin{array}{l}Z \\
\text { value }\end{array}$} & \multirow[t]{2}{*}{$\begin{array}{l}P \\
\text { value }\end{array}$} & \multicolumn{2}{|c|}{$\begin{array}{l}\text { Six months after the } \\
\text { intervention }\end{array}$} & \multirow[t]{2}{*}{$\begin{array}{l}Z \\
\text { value }\end{array}$} & \multirow[t]{2}{*}{$\begin{array}{l}P \\
\text { value }\end{array}$} & \multicolumn{2}{|c|}{$\begin{array}{l}\text { Twelve months after } \\
\text { the intervention }\end{array}$} & \multirow[t]{2}{*}{$\begin{array}{l}Z \\
\text { value }\end{array}$} & \multirow[t]{2}{*}{$\begin{array}{l}P \\
\text { va }\end{array}$} \\
\hline & & $\begin{array}{l}\text { Control } \\
\text { group }\end{array}$ & $\begin{array}{l}\text { Intervention } \\
\text { group }\end{array}$ & & & $\begin{array}{l}\text { Control } \\
\text { group }\end{array}$ & $\begin{array}{l}\text { Intervention } \\
\text { group }\end{array}$ & & & $\begin{array}{l}\text { Control } \\
\text { group }\end{array}$ & $\begin{array}{l}\text { Intervention } \\
\text { group }\end{array}$ & & \\
\hline \multirow[t]{4}{*}{$\begin{array}{l}\text { Nasal } \\
\text { congestion }\end{array}$} & $\begin{array}{l}\text { Grade } \\
0\end{array}$ & 18(31.6) & $20(35.1)$ & -0.310 & 0.757 & $22(38.6)$ & $33(57.9)$ & -2.510 & 0.012 & $24(42.1)$ & $36(63.2)$ & -2.735 & 0.1 \\
\hline & $\begin{array}{l}\text { Grade } \\
1\end{array}$ & $14(24.6)$ & $14(24.6)$ & & & $16(28.1)$ & 16(38.1) & & & 18(31.6) & $17(29.8)$ & & \\
\hline & $\begin{array}{l}\text { Grade } \\
2\end{array}$ & $20(35.0)$ & 18(31.6) & & & $17(29.8)$ & $8(14.0)$ & & & $13(22.8)$ & $4(1.0)$ & & \\
\hline & $\begin{array}{l}\text { Grade } \\
3\end{array}$ & $5(8.8)$ & $5(8.8)$ & & & $2(3.5)$ & $0(0.0)$ & & & $2(3.5)$ & $0(0.0)$ & & \\
\hline \multirow[t]{5}{*}{ Dry mouth } & $\begin{array}{l}\text { Grade } \\
0\end{array}$ & $3(5.3)$ & $4(7.0)$ & -1.322 & 0.186 & $5(8.8)$ & $8(14.0)$ & -2.540 & 0.011 & $15(26.3)$ & $20(35.1)$ & -2.430 & 0.1 \\
\hline & $\begin{array}{l}\text { Grade } \\
1\end{array}$ & $9(15.8)$ & $7(12.3)$ & & & $17(29.8)$ & $24(42.1)$ & & & $22(38.6)$ & $29(50.9)$ & & \\
\hline & $\begin{array}{l}\text { Grade } \\
2\end{array}$ & $22(38.6)$ & $33(57.9)$ & & & $21(36.8)$ & $23(40.4)$ & & & 11(19.3) & $6(10.5)$ & & \\
\hline & $\begin{array}{l}\text { Grade } \\
3\end{array}$ & $23(40.3)$ & $13(22.8)$ & & & $14(24.6)$ & $2(3.5)$ & & & $9(15.8)$ & $2(3.5)$ & & \\
\hline & $\begin{array}{l}\text { Grade } \\
4\end{array}$ & $0(0.0)$ & $0(0.0)$ & & & $0(0.0)$ & $0(0.0)$ & & & $0(0.0)$ & $0(0.0)$ & & \\
\hline \multirow[t]{4}{*}{ Tinnitus } & $\begin{array}{l}\text { Grade } \\
0\end{array}$ & $31(54.4)$ & $25(43.8)$ & -0.493 & 0.622 & $29(50.9)$ & $40(70.2)$ & -2.116 & 0.034 & $32(56.1)$ & $43(75.4)$ & -2.080 & 0.1 \\
\hline & $\begin{array}{l}\text { Grade } \\
1\end{array}$ & $6(10.5)$ & $13(22.8)$ & & & $15(26.3)$ & 11(19.3) & & & $17(29.8)$ & $13(22.8)$ & & \\
\hline & $\begin{array}{l}\text { Grade } \\
2\end{array}$ & 15(26.3) & 16(28.1) & & & 11(19.3) & $3(5.2)$ & & & $6(10.5)$ & 1(1.8) & & \\
\hline & $\begin{array}{l}\text { Grade } \\
3\end{array}$ & $5(8.8)$ & $3(5.3)$ & & & $2(2.5)$ & $3(5.3)$ & & & $2(3.5)$ & $0(0.0)$ & & \\
\hline \multirow[t]{3}{*}{ Trismus } & $\begin{array}{l}\text { Grade } \\
0\end{array}$ & $45(78.9)$ & $51(89.4)$ & -1.505 & 0.132 & 42(73.7) & $52(91.2)$ & -2.405 & 0.016 & $44(77.2)$ & $53(93.0)$ & -2.295 & 0.1 \\
\hline & $\begin{array}{l}\text { Grade } \\
1\end{array}$ & 11(19.3) & $5(8.8)$ & & & $14(24.5)$ & $4(7.0)$ & & & $13(22.8)$ & $3(5.2)$ & & \\
\hline & $\begin{array}{l}\text { Grade } \\
2\end{array}$ & $1(1.8)$ & $1(1.8)$ & & & $1(1.8)$ & $1(1.8)$ & & & $0(0.0)$ & $1(1.8)$ & & \\
\hline \multirow[t]{3}{*}{$\begin{array}{l}\text { Neck } \\
\text { fibrosis }\end{array}$} & $\begin{array}{l}\text { Grade } \\
0\end{array}$ & $39(68.4)$ & $47(82.4)$ & -1.667 & 0.095 & $35(61.4)$ & $47(82.4)$ & -2.471 & 0.013 & $38(66.7)$ & $50(87.7)$ & -2.638 & 0.1 \\
\hline & $\begin{array}{l}\text { Grade } \\
1\end{array}$ & $14(24.6)$ & $7(12.3)$ & & & $20(35.1)$ & $9(15.8)$ & & & 17(29.8) & $6(10.5)$ & & \\
\hline & $\begin{array}{l}\text { Grade } \\
2\end{array}$ & $4(7.0)$ & $3(5.3)$ & & & $2(3.5)$ & $1(1.8)$ & & & $2(3.5)$ & $1(1.8)$ & & \\
\hline
\end{tabular}

\subsection{The quality of life symptom domain scores before and after the intervention}

The symptom domains of quality of life between the two groups showed no significant difference in the scores before and after the intervention ( $P>0.05)$. After 6 months of intervention, the scores of head and neck pain, swallowing function, sensory problems, and language problems were found to be lowered in the intervention group than those in the control group $(P<0.05)$, while there was no significant difference in the other symptom scores $(P>0.05)$. After 12 months of intervention, the scores of symptom domains were found to be lower in the intervention group than those in the control group $(P<0.05)$; using the two -sample repeated measurement ANOVA, the results showed that except for the language problems, the scores of each symptom domain of quality of life lowered in the intervention group than those in the control group after 6 months and 12 months of intervention, and with the extension of the intervention time, the scores of symptom domains of the quality of life in the intervention group were found to decrease,(Table 5).

Table 4 Comparison of cancer fatigue between the two groups

before intervention $(n=114)$ 


\begin{tabular}{|c|c|c|c|c|c|}
\hline Project & Before intervention & Six months after the intervention & Twelve months after the intervention & $F$ value & $P$ value \\
\hline \multicolumn{6}{|l|}{ The total fatigue } \\
\hline Control group & $26.46 \pm 4.21$ & $24.09 \pm 3.21$ & $22.61 \pm 2.91$ & $F_{1}=39.297$ & $\varangle 0.001$ \\
\hline Intervention group & $26.65 \pm 3.51$ & $19.86 \pm 3.63$ & $15.75 \pm 3.08$ & $F_{2}=18.475$ & $₫ 0.001$ \\
\hline$t$ value & -0.266 & -6.586 & -12.247 & $F_{3}=189.465$ & $\varangle 0.001$ \\
\hline$P$ value & 0.791 & $\otimes 0.001$ & $\bowtie 0.001$ & & \\
\hline \multicolumn{6}{|l|}{ Physical fatigue } \\
\hline Control group & $10.82 \pm 3.10$ & $9.91 \pm 2.54$ & $9.21 \pm 2.45$ & $F_{1}=9.371$ & $\bowtie 0.001$ \\
\hline Intervention group & $9.73 \pm 3.18$ & $7.63 \pm 2.26$ & $6.14 \pm 1.90$ & $F_{2}=6.311$ & 0.015 \\
\hline$t$ value & -1.848 & -5.055 & -7.476 & $F_{3}=55.863$ & $\varangle 0.001$ \\
\hline$P$ value & 0.067 & $\varangle 0.001$ & $\bowtie 0.001$ & & \\
\hline \multicolumn{6}{|l|}{ Emotional fatigue } \\
\hline Control group & $8.94 \pm 1.24$ & $8.08 \pm 1.53$ & $7.684 \pm 1.48$ & $F_{1}=14.537$ & $₫ 0.001$ \\
\hline Intervention group & $9.28 \pm 1.57$ & $7.31 \pm 1.66$ & $6.070 \pm 1.57$ & $F_{2}=5.650$ & 0.021 \\
\hline$t$ value & 1.257 & -2.575 & -5.677 & $F_{3}=79.988$ & $\varangle 0.001$ \\
\hline$P$ value & 0.211 & 0.011 & 0.003 & & \\
\hline \multicolumn{6}{|l|}{ Cognitive fatigue } \\
\hline Control group & $6.87 \pm 1.56$ & $5.67 \pm 1.73$ & $5.71 \pm 1.44$ & $F_{1}=32.947$ & $\otimes 0.001$ \\
\hline Intervention group & $6.94 \pm 1.65$ & $4.91 \pm 1.47$ & $3.52 \pm 1.50$ & $F_{2}=8.819$ & 0.004 \\
\hline$t$ value & 0.233 & -2.506 & -7.936 & $F_{3}=92.185$ & $\varangle 0.001$ \\
\hline$P$ value & 0.816 & 0.014 & $\otimes 0.001$ & & \\
\hline
\end{tabular}

Notel $F 1$ is the time effect; $F 2$ is the inter group effect; $F 3$ is the interaction effect of time and grouping.

Table 5 Comparison of quality of life in various fields between the two groups before intervention $(n=114)$ 


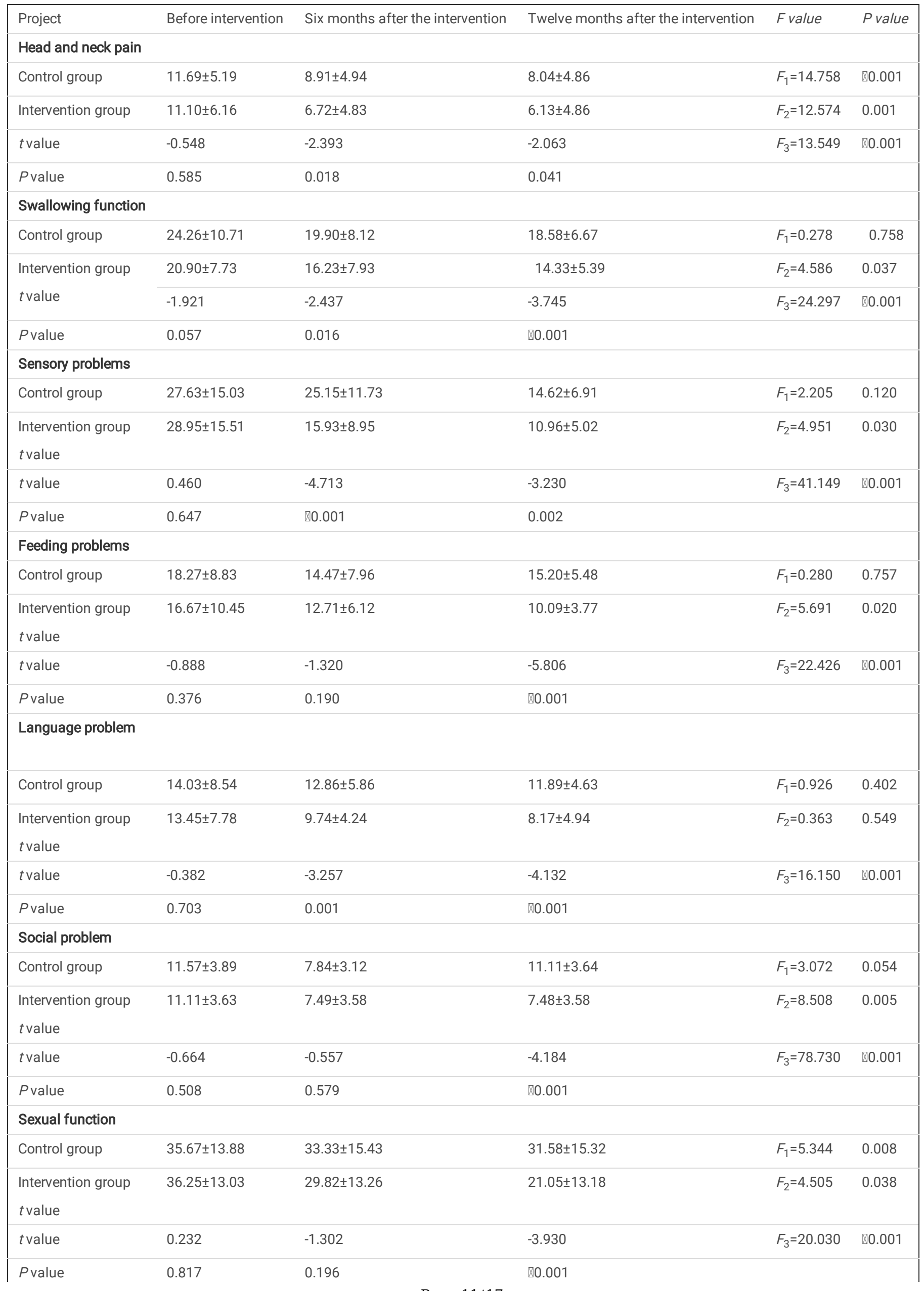


Notel $F 1$ is the time effect; $F 2$ is the inter group effect; $F 3$ is the interaction effect of time and groupin

\section{Discussion}

4.1 The construction of the mHealth platform is of great significance for the home-based management of NPC patients

NPC as a chronic disease is highly prevalent in the old, rural, border, and poor areas of Guangxi (ZielińskaWięczkowska, 2010). After discharge, the patients, especially those in the rural areas, fail to achieve timely professional help and guidance from the medical personnel due to the long -distance or economic conditions. Dai has also proved that the discharged patients are more willing to receive professional guidance or one-to-one nursing service without leaving their homes (Ming-Hui, Li, Qiao-Qin, Nursing, \& University, 2013). Therefore, it is imperative to innovate the form of continuing nursing and develop diversified service modes. The mobile internet technology has introduced a brand-new improvised mode for stay -at -home and instant medical care, promoting medical knowledge sharing and doctor-patient or nurse -patient interaction, improving the level of hospital clinical nursing information construction at a deeper level, and diversifying the work of nurses (Xinlei, Shui, Jing, \& Center, 2018). Chinese scholars have developed the mHealth nursing platform and applied it for the health management of diabetes, bone arthroplasty, and enterostomy (Jie et al., 2018). However, NPC has not been related to the "Internet +"-based continuous care. Therefore, this study conforms to the development needs of the times for building a continuous care management platform for the NPC patients with functions such as questioning, video playback, graphic editing, knowledge push, questionnaire statistics, and message reminders, which would provide the NPC patients with "immediate care without leaving home" services and overcome the limitations of current community conditions and the shortcomings of the hospital services. Up to now, there are 7 registered communities of the NPC continuous care platform with 19 medical staff, where the utilization rate has reached $98 \%$. The doctor-patient or nurse-patient interactions summed to be more than 300 times, and the cumulative reading volume was more than 2280 times, indicating the establishment of the internet platform for NPC. It not only innovates the continuous nursing method, by building an interactive platform between the medical staff and patients after the hospital, but more importantly accelerates the dissemination of health knowledge, improving the level of information-based nursing services, as well as patient satisfaction, and benefits the majority of patients. It also indirectly illustrated the desire of the patients subjected to home rehabilitation for gathering knowledge about disease and health and the lack of access to the previous channels. Therefore, future studies should reinforce the combination of information technology and medical care, for continuously standardizing and innovating the form of continuous management.

\subsection{The application of the mHealth management can reduce the incidence of toxic and side effects}

The toxic and side effects of radiotherapy were found to be alleviated by effective nursing. This study showed that the application of the mHealth to carry out continuous nursing services can reduce the incidence of symptoms like nasal congestion, dry mouth, tinnitus, neck fibrosis, and difficulty in the opening mouth $(P<0.05)$. Thus, the mHealth platform might be applicable for enlightening the patients with advanced knowledge of nursing, through dynamic video, and personalized counseling, that would effectively cater to the needs of the patients to get the nursing service and urge the patients to take effective nursing measures according to the inquiry function to improve their compliance and self-care skills, and finally reducing the symptoms like dry mouth, tinnitus, nasal congestion, and neck in the mouth. The degree of the side effects such as fibrosis and difficulty in opening the mouth were also taken into consideration.

\section{3 the mHealth management can reduce the degree of cancer-related fatigue}

Studies have shown gender, chemoradiotherapy, depression, pain, sleep disorders to be closely related to CRF in NPC patients. Appropriate exercises can effectively improve the degree of CRF, and high compliance aerobic exercises have been found to show better efficacy than resistance exercises (Ellen, Olga, \& Van, 2018). Other studies have demonstrated that therapies assisting the patients in recognizing and correcting the erroneous ideas and behaviors, starting with the triggers of negative symptoms, have a significant clinical effect in reducing the $\mathrm{CRF}$ and functionally impairing the cancer survivors.(Abrahams $\mathrm{H} \mathrm{J} \mathrm{G}$, 2017; Gielissen, Verhagen, Witjes, \& Bleijenberg, 2006). This study showed that the mHealth can be implemented on extending the care services in a highly significant manner to improve the CRF of patients at home. This may be because the service based on the Internet platform provided a convenient condition for professional consultation and a good environment for emotional communication. It promoted the establishment of a virtuous circle for the mutual improvement of the somatic symptoms and negative emotions. During consultation, the medical staff solves the patients' doubts, providing methods to improve the symptoms, and change their cognition. Through communication, the medical staff can understand the patients' false cognition, carry out the targeted intervention, reconstructing the patients' cognitive concept, and improving patients' sense of fatigue. In addition, the head and neck exercise belonging to the aerobic exercises affects by reducing the patients' sense of CRF. With the help of the internet platform, online communication with the patients not only provides nursing methods and supervision to the patients but also provides emotional and information support, to change the patients' cognition and reduce fatigue.

\section{4 the mHealth application can improve the QOL of patients}

QOL is an important component for evaluating the health care system, and improving the quality of life of the tumor patients at home is the primary goal of implementing continuous nursing services. The 5-year survival rates of the NPC patients have reached more than $80 \%$ (Sheng-Fa et al., 2013). However, the chronic specific symptoms, such as head and neck pain, swallowing function, sensory problems, language problems, difficulty in eating, dry mouth, viscous saliva, and a variety of derived negative emotions, such as depression and anxiety, make the survivors of NPC to further suffer from physical and mental suffering, hampering the QOL (Trotti A, 2003). This research is based on the mHealth to carry out continual nursing for NPC. The results showed that the scores of the 7 symptom areas of pain, swallowing, sensation, eating, language, social contact, and sexual function in the observation group were all lower than those in the control group after intervention $(P<0.05)$. In other words, the QOL of patients based on the extended care of network platform is better than the traditional follow-up management. This is similar to the research on applying "Internet + " in the chronic disease management model for type 2 diabetes by

Page $12 / 17$ 
Yun(Hai-Ling, Ping, Wen-Xiu, \& Xiao-Rong, 2016), and the results of Dai in designing and applying the networked management system for the stroke patients (JIA Jing, 2018). The reasons may be: (1), Combining the continuity of care with the "Internet +" to carry out the network management service would overcome the space and time constraints, and achieve seamless guidance and supervision, conducive to improve the health outcomes of the patients and improving the QOL of the patients. (2) The information management and emotional support can assist the patients in performing rehabilitation nursing and functional exercise, and that would reduce the degree of various specific symptoms in the patients. The internet platform is always the carrier, and the most important factor for promoting the rehabilitation of the patients is the pertinence, rationality, and standardization of the content. (3) The "Internet +" continuity of care can effectively prevent the patients from returning to hospitals frequently, reducing the cost of medical services as well as the burden. (4) The continuity of care based on the "Internet + " is extended to home, and achieving the continuity of information, management and relationship.

\section{Limitations}

This study was a single-center study, and the number of included cases was relatively small. One of the inclusion criteria of the study subjects was the ability to use smartphones, and these limitations might affect the study results. In the future, the application of the platform can be further promoted and multicenter, large-sample application research should be performed to improve the credibility of the research.

\section{Conclusion}

This study provided professional, continuous, and overall extended care for the NPC discharged patients constructing the mHealth platform and implementing a continuous nursing scheme centered on the patient needs. The platform guides the patients to master the correct knowledge of the disease as well as the rehabilitation and exercise methods, for improving the self-care ability, reducing the toxic and side effects of radiotherapy and cancer fatigue, improving the $\mathrm{QOL}$, and meeting the demands for long-term management. This study can provide reference for follow-up management of all patients with chronic diseases.

\section{Abbreviations}

mHealth Mobile Health

NPC Nasopharyngeal carcinoma

QOL The quality of life

CRF Cancer-related fatigue

\section{Declarations}

(1) Ethics approval and consent to participate:

This study was approved by the Research Committee of Guangxi Medical University Hospital (Approval Number:2019 (KY-E-136)). If the patient met the inclusion criteria, the experts from the continuation care team would explain the purpose and process of the study to the patient, ensuring that their personal information is only used for this study. We confirmed that the participants understood the purpose of the trial and that is required of them during the informed consent process. Although the nursing staff was often present during the consent process, all the patients provided informed consent independently.

(2) Consent for publication: Not applicable.

(3) Availability of data and material: The data that support the findings of this study are not openly available due to human data and are available from the corresponding author upon reasonable request.

(4) Competing interests: The authors declare that they have no competing interests" in this section.

(5) Funding: Chinese Nursing Association Project [grant numbers ZHKY201919]

(6) Authors' contributions: LTT implement of the research plan and analyzed and interpreted the patient data regarding the NPC disease and was a major contributor in writing the manuscript. YL is responsible for the quality review of the entire research program and statistical data. QLY is responsible for platform maintenance, implement of the research and statistical data; ZYX, ZJW and LJY are responsible for data collection. All authors read and approved the final manuscript.

(7) Acknowledgements: Thanks to Director Wang Rensheng and Chief Nurse Liao Jinlian for their support to the entire study.

(8) All authors declare that all methods were performed in accordance with the relevant guidelines and regulations.

\section{References}

1. Abrahams H J G, G. M. F. M., Donders R R T, etal. (2017). The efficacy of Internet-based cognitive behavioral therapy for severely fatigued survivors of breast cancer compared with care as usual: A randomized controlled trial. Cancer, 123(19), 3825-3834.

2. Chang, E. T., \& Adami, H. O. (2006). The enigmatic epidemiology of nasopharyngeal carcinoma. Cancer Epidemiol Biomarkers Prev, 15(10), $1765-1777$. doi:10.1158/1055-9965.epi-06-0353

Page $13 / 17$ 
3. Chie, W. C., Hong, R. L., Lai, C. C., Ting, L. L., \& Hsu, M. M. (2003). Quality of life in patients of nasopharyngeal carcinoma: Validation of the Taiwan Chinese version of the EORTC QLQ-C30 and the EORTC QLQ-H\&N35. Quality of Life Research, 12(1), 93-98.

4. China, N. H. a. F. P. C. o. t. P. s. R. o. (2017). National Nursing Career Development Plan (2016-2020). Chinese Nursing Management, 17(001), 1-5.

5. Chow, S. K. Y., Wong, F. K. Y., Chan, T. M. F., Chung, L. Y. F., \& Lee, R. P. L. (2010). Community nursing services for postdischarge chronically ill patients. Journal of Clinical Nursing, 17(7B), 260-271.

6. Cox J D, S. J. A., Pajak T F. (1995). Toxicity Criteria of the Radiation Therapy Oncology Group (RTOG) and the European Organization for Research and Treatment of Cancer (EORTC). Int J Radiol Oncol Biol Phys, 31(5), 1341-1346.

7. Ellen, K., Olga, H., \& Van, d. F.-C. C. M. (2018). The effect of exercise on cancer-related fatigue in cancer survivors: a systematic review and meta-analysis. Neuropsychiatric Disease \& Treatment, 14, 479-494.

8. Feng, S., Liang, Z., Zhang, R., Liao, W., Chen, Y., Fan, Y., \& Li, H. (2017). Effects of mobile phone WeChat services improve adherence to corticosteroid nasal spray treatment for chronic rhinosinusitis after functional endoscopic sinus surgery: a 3-month follow-up study. Eur Arch Otorhinolaryngol, $274(3), 1-9$.

9. Gao, C., Zhou, L., Liu, Z., Wang, H., \& Bowers, B. (2017). Mobile application for diabetes self-management in China: Do they fit for older adults? International Journal of Medical Informatics, 101(5), 68-74.

10. Gielissen, M. F. M., Verhagen, S., Witjes, F., \& Bleijenberg, G. (2006). Effects of cognitive behavior therapy in severely fatigued disease-free cancer patients compared with patients waiting for cognitive behavior therapy: a randomized controlled trial. Journal of Clinical Oncology, 24(30), 4882-4887.

11. Gift, A. G., Stommel, M., Jablonski, A., \& Given, W. (2003). A cluster of symptoms over time in patients with lung cancer. Nursing Research, 52(6), 393-400.

12. GUO Ming juan, Y. L. (2017). The practice of applying mobile health App on continuing nursing of nasopharyngeal carcinoma patients. Journal of Nursing Adminstration, 17(11), 825-827.

13. Hai-Ling, Y., Ping, W., Wen-Xiu, H., \& Xiao-Rong, L. (2016). Design and application of continuing care service platform under the linkage of hospitalcommunity-family. Chinese Journal of Nursing, 51(9), 1133-1137.

14. Hui, L. I., Qian, L. U., Ping, Y., Wan-Rong, L., Hui-Yuan, W., \& Su-Mei, L. I. (2015). Research on symptoms and transitional care needs of hepatocellular carcinoma patients following hepatectomy. Chinese Journal of Nursing, 50(6), 48-52.

15. Jemal, A., Bray, F., Center, M. M., Ferlay, J., Ward, E., \& Forman, D. (2011). Global cancer statistics. CA Cancer J Clin, 61(2), 69-90. doi:10.3322/caac.20107

16. JIA Jing, X. J., QIU Xiaoxi. (2018). Application of hospital-community-family home care mobile App in patients with stress urinary incontinence. Chinese Journal of Nursing, 053(005), 533-536.

17. Jianbo, L., \& Haiying, G. (2009). Influence of telephone follow-up on quality of life of nasopharyngeal carcinoma discharged patients after radiotherapy. Chinese Nursing Research, 23(5), 1259-1260.

18. Jie, W., Yahui, T., Yingqing, J., Hongxia, Z., Hui, G., Rong, W., . . Luoluo, G. (2018). The effectiveness of extended care based on Internet and Home Care Platform for Orthopedics after hip replacement surgery in China. Journal of Clinical Nursing, 27((21-22)), 4077-4088.

19. King, M., Jones, L., Mccarthy, O., Rogers, M., \& Nazareth, I. (2009). Development and pilot evaluation of a complex intervention to improve experienced continuity of care in patients with cancer. British Journal of Cancer, 100(2), 274-280.

20. Lijun, Z., Shuang, C., \& Hui, Z. (2018). Effect of Continuity Nursing on the Curative Effect,NRS2002 Score and Compliance of Patients with Nasopharyngeal Carcinoma Undergoing Radiotherapy. Sichuan Medical Journal, 39(1), 98-101.

21. Luo Huiyu, Z. F., Qi Rong, Lin Ya. (2017). The establishment of "Internet Plus" health education programme for cancer patients. Chinese Journal of Nursing, 52(012), 1482-1485.

22. Min, L., Guohong, L. I., \& Yang, Z. (2015). Current status of transitional care for discharged patients: a review. Chinese Nursing Management, 15(12), 122125.

23. Ming-Hui, D., Li, Y., Qiao-Qin, W., Nursing, S. O., \& University, P. (2013). The investigation and analysis of transitional care needs among discharged patients. Chinese Nursing Management, 13(10), 27-30.

24. Okuyama, T., Akechi, T., Kugaya, A., Okamura, H., Shima, Y., Maruguchi, M., . . Uchitomi, Y. (2000). Development and Validation of the Cancer Fatigue Scale: A Brief, Three-Dimensional, Self-Rating Scale for Assessment of Fatigue in Cancer Patients. J Pain Symptom Manage, $19(1), 5-14$.

25. Qiao-Qin, W., Li, Y., Shu-Xiao, H., Nursing, S. O., \& University, P. (2013). A qualitative study of the current status and existing problems of hospital-based transitional care. Chinese Nursing Management, 13(10), 43-46.

26. Sheng-Fa, S. U., Chong, Z., Fei, H., Chun-Yan, C., Wei-Wei, X., \& Xue-Ming, S. (2013). Long-term outcome of nasopharyngeal carcinoma patients treated withintensity-modulated radiotherapy. Chinese Journal of Cancer Prevention and Treatment, 20(11), 853-858.

27. Shi-Ying, W., Shu-Hua, X. I., Yi-Gang, L. V., \& Jin-Hua, W. (2009). Analysis of Problems and Counter Measures in Continued-nursing for Discharged Patients. Nursing Journal of Chinese Peoples Liberation Army, 26(3), 24-26.

28. Shi, R.-C., Meng, A.-F., Zhou, W.-L., Yu, X.-Y., Huang, X.-E., Ji, A.-J., \& Chen, L. (2015). Effects of Home Nursing Intervention on the Quality of Life of Patients with Nasopharyngeal Carcinoma after Radiotherapy and Chemotherapy. Asian Pacific Journal of Cancer Prevention, 16(16), 7117-7121. doi:10.7314/apjcp.2015.16.16.7117

29. Shu-Hua, X. I., Ji-Jun, Z., \& Jian-Hua, Z. (2007). Discharge planning in Cheng Kung University Hospital and the implication. Chinese Journal of Nursing, 42(4), 341-342.

30. Strazzulla, A., Barreca, G. S., Giancotti, A., Pisani, V., \& Torti, C. (2015). Nasopharyngeal carcinoma: review of the literature with a focus on therapeutical implications. Infez Med, 23(3), 224-229. 
31. Tang, L. L., Chen, W. Q., Xue, W. Q., He, Y. Q., Zheng, R. S., Zeng, Y. X., \& Jia, W. H. (2016). Global trends in incidence and mortality of nasopharyngeal carcinoma. Cancer Letters, 22-30.

32. Trotti A, B. L. A., Epstein J B, et al. (2003). Mucositis incidence, severity and associated outcomes in patients with head and neck cancer receiving radiotherapy with or without chemotherapy: a systematic literature review. Radiotherapy \& Oncology, 66(3), 253-262. doi:10.1016/S0167-8140(02)004048

33. WANG Shao-ling, H. J.-y., ZHOU Jia-yi. (2009). Development of evidence-based transitional care practice for chronic obstructive pulmonary disease. Chinese Journal of Nursing, 44(5), 431-434.

34. Xiao, C., Hanlon, A., Zhang, Q., Ang, K., Rosenthal, D. I., Nguyen-Tan, P. F., . . Bruner, D. W. (2013). Symptom clusters in patients with head and neck cancer receiving concurrent chemoradiotherapy. Oral Oncology, 49(4), 360-366.

35. Xinlei, M. A., Shui, Y. U., Jing, M. A., \& Center, C. T. (2018). Application of "Internet plus" to continuous nursing of patients underwent percutaneous coronary stent implantation. Chinese Nursing Management, 18(9), 92-96.

36. Yi, S., \& Qiang, W. (2017). Investigation on symptom clusters in patients with nasopharyngeal carcinoma undergoing concurrent chemoradiation therapy. Nursing Research of China.

37. Ying, L. (2017). Construction of an M-Health Based information support program for women with Breast cancer during diagnosis and treatment process. Second Military Medical University, Shanghai.

38. ZielińskaWięczkowska, H. (2010). Quality of Life in Cancer Patients undergoing Chemotherapy. Contemporary Oncology, $24(3), 204$.

\section{Figures}

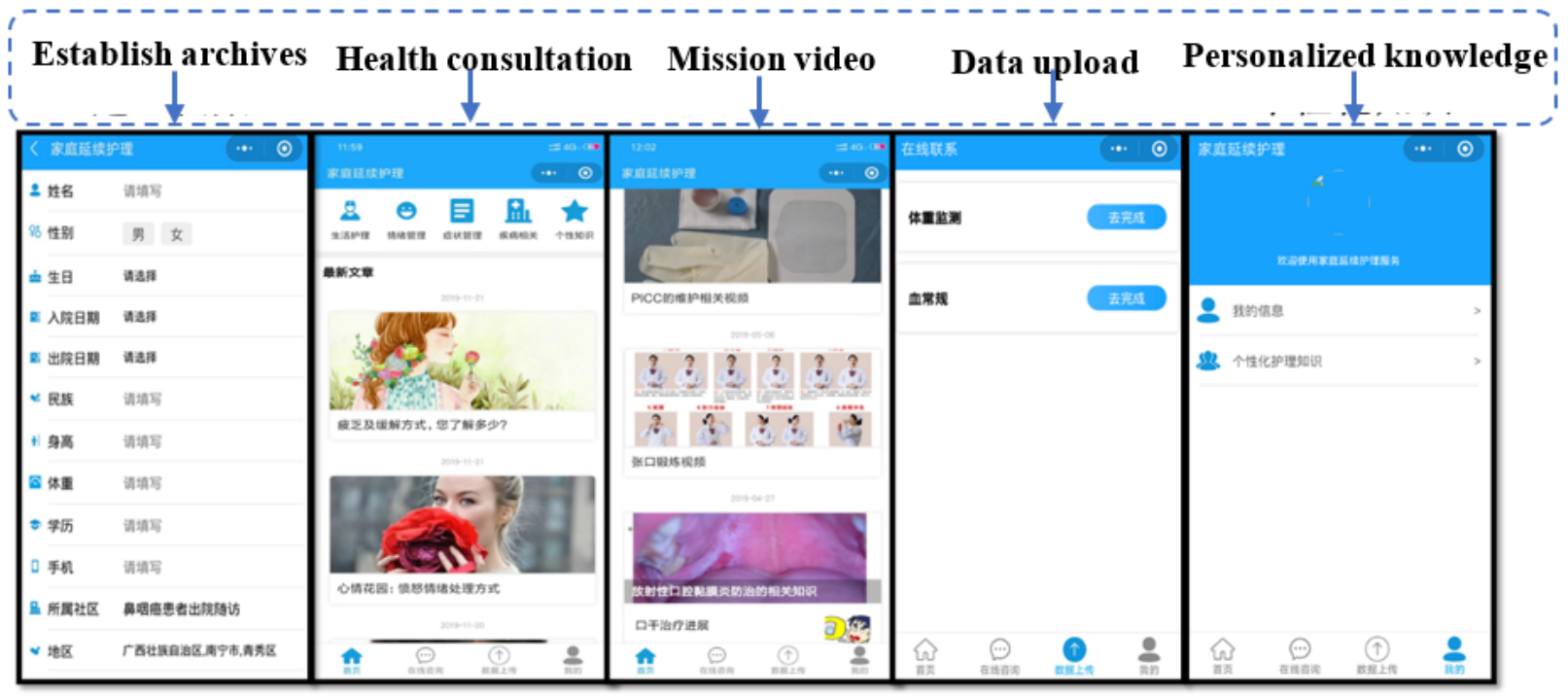

Figure 1

Patient side

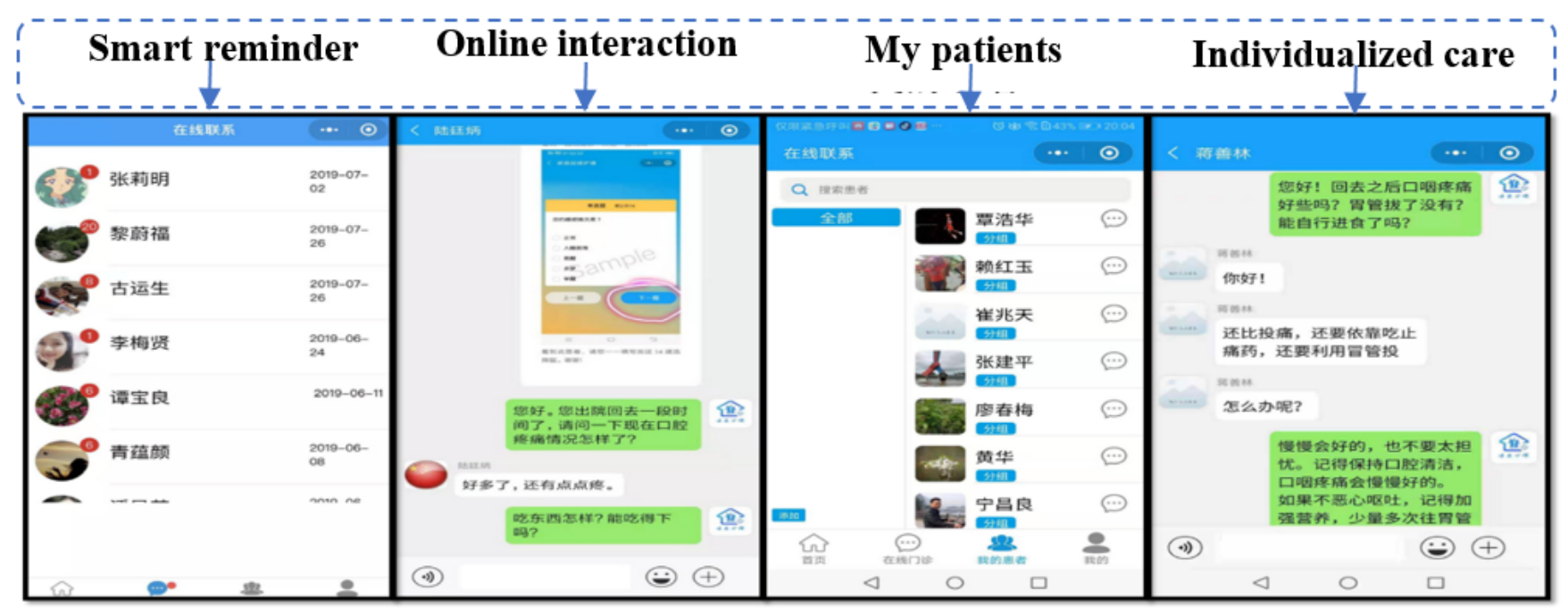

Figure 2 
Medical service terminal

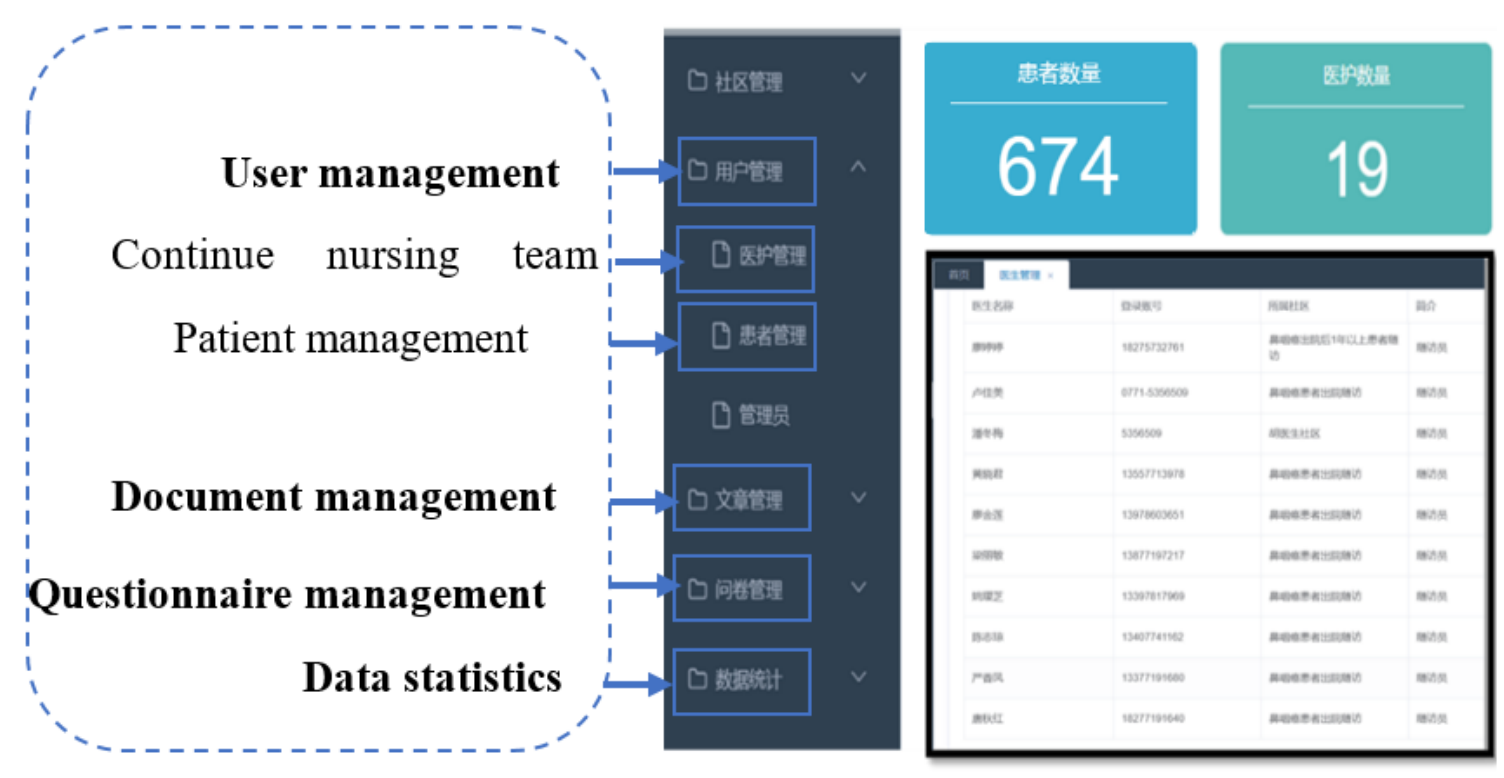

Figure 3

System management platform

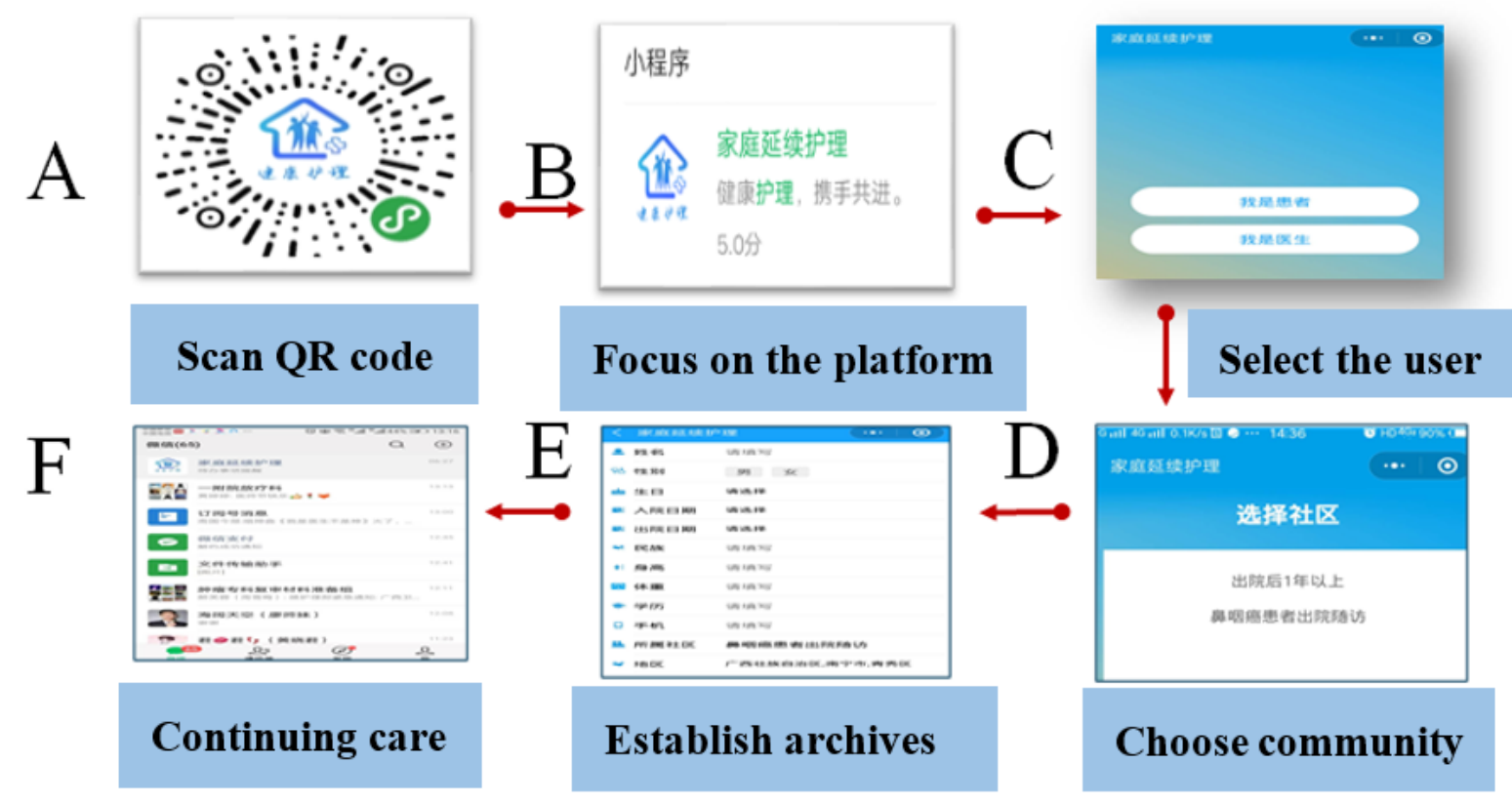

Figure 4

Access platform flow chart 


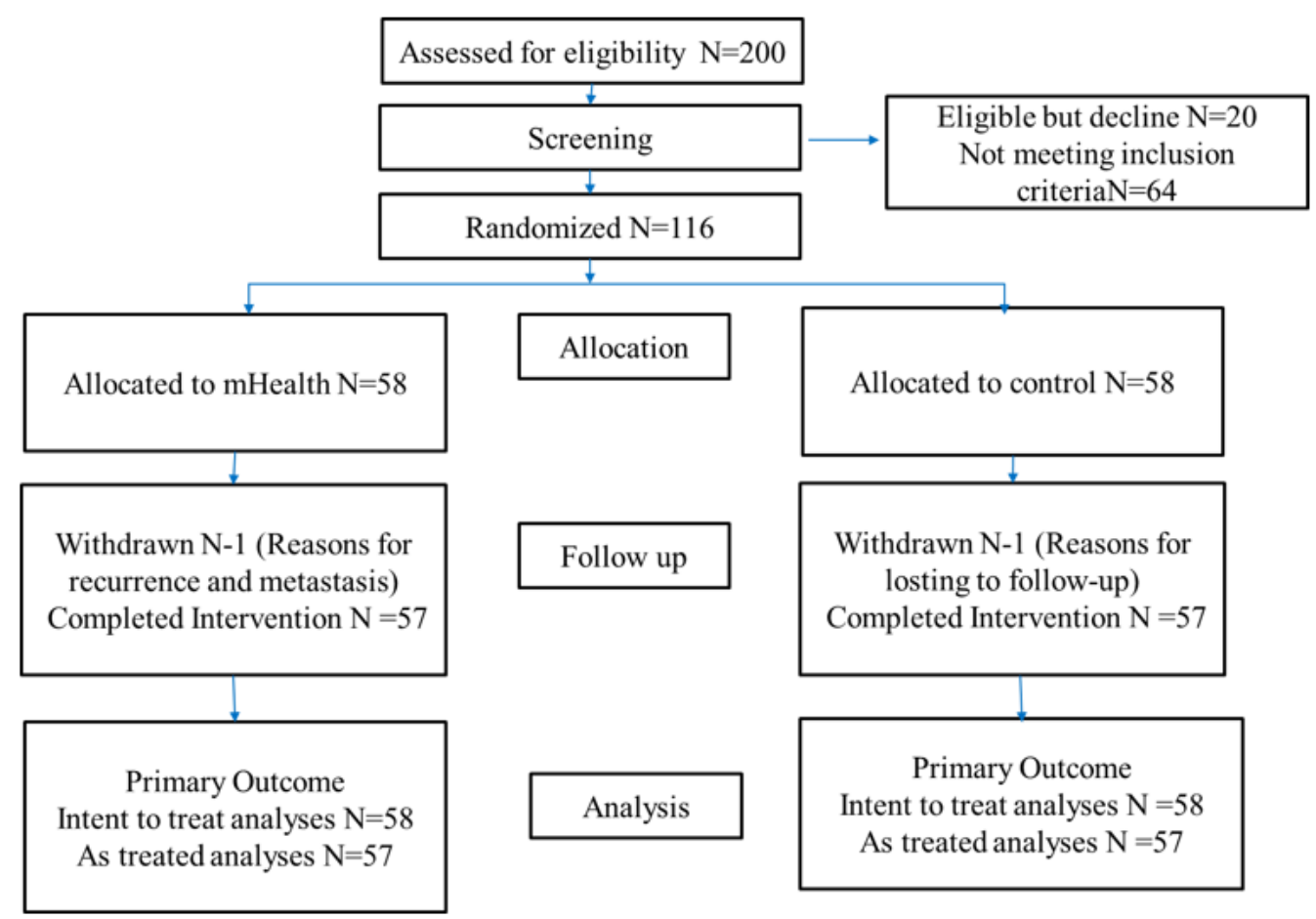

Figure 5

CONSORT

\section{Supplementary Files}

This is a list of supplementary files associated with this preprint. Click to download.

- SupplementaryFileCONSORT.doc 